\section{Role of Laparoscopy in Complicated Meckel's Diverticulum in Pediatrics}

Received: October 06, 2016; Accepted: October 17, 2016; Published: October 21, 2016

Meckel diverticulum (MD) (Figures 1 and 2) is the most widely recognized inborn variation from the norm of the Gastrointestinal system. It occurs due to non-conclusion of the omphalomesenteric channel, which should pulverize in the fifth -seventh gestational weeks. At the point when the MD is symptomatic, it may be responsible for severe episodes of intestinal bleeding, intussusception, bowel obstruction, or recurrent abdominal pain with repeated vomiting and/or nausea. Increasing number of reports on the use of laparoscopy in children with Meckel's diverticulum was observed. The purpose of this study was to review our department's experience with laparoscopy and to reiterate that laparoscopy is a viable option, even for pediatric patients with complicated Meckel diverticulum.

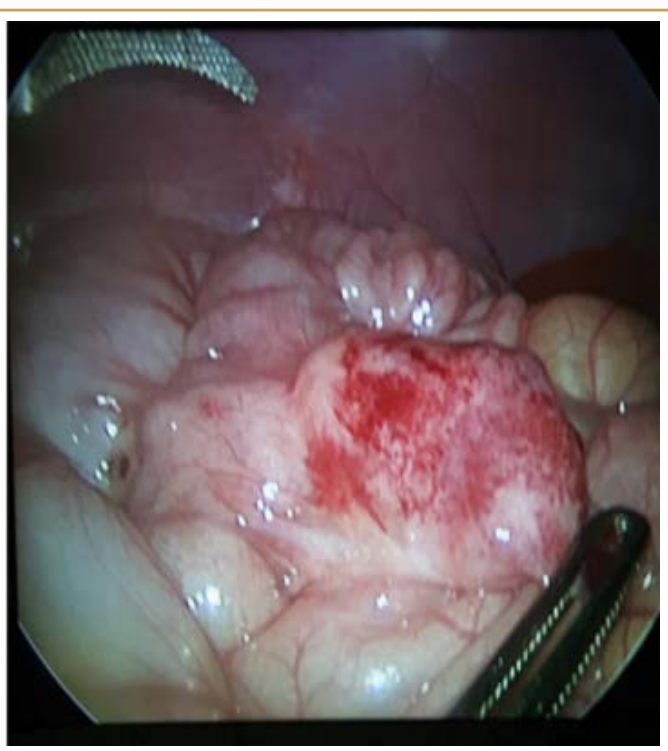

Figure 1 Laparoscopic view showing Meckel Diverticulum.

\section{Hamdi Louati, Riadh Jouini, Yosra Ben Ahmed, Awatef Charieg, Faouzi Nouira, and Said Jlidi}

Department of Pediatric Surgery "B", Children Hospital, Tunis, Tunisia

Corresponding author: Hamdi Louati

Đdrhamdilouati85@yahoo.com

Department of Pediatric Surgery "B", Children Hospital, Tunis, Tunisia.

Tel: 0021652225719

Citation: Louati H, Jouini R, Ahmed YB, et al. Role of Laparoscopy in Complicated Meckel's Diverticulum in Pediatrics. J Univer Surg. 2016, 4:4.

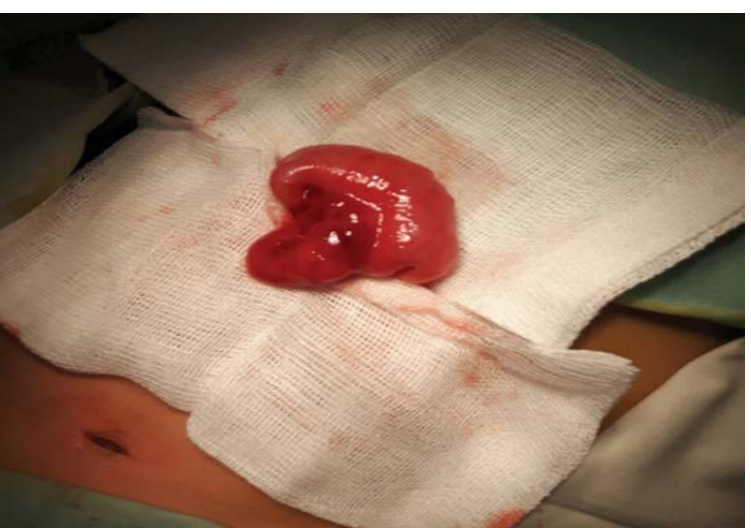

Figure 2 Trans-umbilical extraction of the Meckel Diverticulum. 